American Journal of Applied Sciences 8 (6): 594-602, 2011

ISSN 1546-9239

(C) 2011 Science Publications

\title{
Repower and Evaluation of New Power of Synchronous Generators
}

\author{
${ }^{1}$ S.P.Y. Santos, ${ }^{2}$ E. Delbone, ${ }^{3}$ E.F. Carvalho and ${ }^{4}$ L.N. Martins \\ ${ }^{1}$ Department of Electrical Engineering, Santa Cecilia University, Unisanta, \\ Oswaldo Cruz Street 277, Santos, 11045-907, Brazil \\ ${ }^{2}$ Department of Electrical Engineering, Paulista University, UNIP, São Paulo, \\ ${ }^{3}$ SENAI Anchieta Technology Faculty, Sao Paulo, SP, \\ ${ }^{4}$ Department of Electrical Engineering, Federal University of Uberlandia, \\ UFU, Uberlandia, MG, Brazil
}

\begin{abstract}
Problem Statement: Useful life of winding isolation is about 30 years. It can be reduced when it is submitted to overloads or when it is worked in aggressive environments. Approach: When retrofit is done, an increasing to superior isolation class is recommendable. So, generator capacity can be increased and pay back could be excellent justifying the investment. Result: Several Brazilian's experiences successfully showed the retrofit with repower, for example many GE generators at Henry Borden Power Plant in Cubatão, São Paulo, whose power had increased up to 50\%. This study aimed at presenting two cases of rewound with repower, changing the old insulating materials by other modern ones in substantial increases of power about $30 \%$. The discussion also included how to determine the new power obtained after the repower and before the load tests. In large machines, the load tests are accomplished with machine connected with network power system and they needed special attention and care. In other words, they are critical tests. The calculations of the field current of full load generator for determining field temperature elevation, indirect tests (no load) are done. Which are the methods that present reliable results? Conclusion: This study showed a confrontation among three studied methods, ASA, IEEE 115 and General Method with their theoretical analyze. ASA method was normalized in many countries; in Brazilian showed in NBR-5052. In IEEE 115, the method is named "Phasor Diagram Analysis-Salient-pole Machines". General Method is an academic treatment with better theoretical explanation.
\end{abstract}

Key words: Synchronous Generator (SG), American Standard Association (ASA), general method, Synchronous Reactance (SR), load voltage, magnetic circuit, phasor diagram analysis

\section{INTRODUCTION}

This study is based on two CEMIG GE generators successfully repowered in 2007 by WEG according to Table 1.

It is also based on eight 20-pole, 11-kV, EMAE GE generators, which were repowered from 1995 until 2007 to obtain new power with increase up to $50 \%$, when they will changed from $\mathrm{B}$ to $\mathrm{F}$ class according to Table 2.

Table 1: Generators repowered by WEG-CEMIG

\begin{tabular}{lll}
\hline Generator & 1 & 2 \\
\hline Earlier power (MW) & 28.241 & 28.241 \\
After Repower (MW) & 36.948 & 36.948 \\
\hline
\end{tabular}

Table 2: S G repowered in hydroelectric henry borden power plantcubatão/SP

\begin{tabular}{lllllllll}
\hline Generator & 1 & 2 & 3 & 4 & 5 & 6 & 7 & 8 \\
\hline Earlier power & 33 & 33 & 55 & 55 & 55 & 55 & 55 & 55 \\
After repower & 43 & 39 & 69 & 78 & 69 & 76 & 66 & 69 \\
\hline
\end{tabular}

\section{MATERIALS AND METHODS}

After repowered, it must be confirmed with final tests in nominal load if they could guarantee the new projected values.

In large machines, the test with nominal load implies in putting it in parallel with electrical network system. Before test, it is recommendable to guarantee new parameters as well as to confirm planned range temperature. It is possible with normalized tests but no loading ones. This study aims at establishing a critical discussion about tests, without considerations about harmonic distortion. Methods are to be in steady state condition and everything is modeled in frequency dominion.

Stator: In accordance with IEEE Guide: Test Procedures for Synchronous Machines: IEEE 115-1995, determination of Stator temperature elevation can be done with several methods.

Corresponding Author: S.P.y Santos, Santa Cecilia University, UNISANTA, Department of Electrical Engineering, Santos, SP, Brazil 


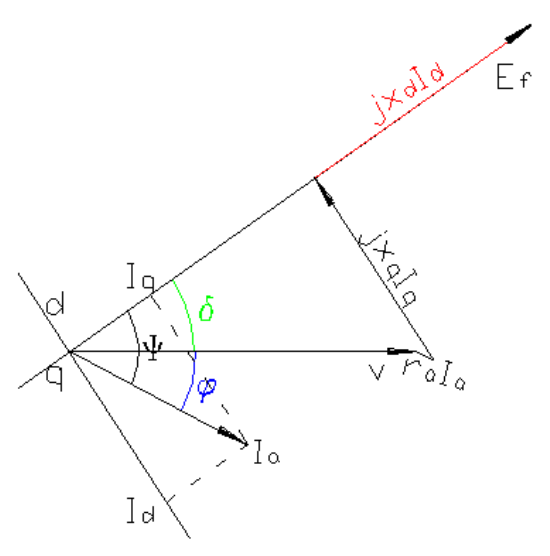

Fig. 1: $\mathrm{E}_{\mathrm{f}}$ determination

However the load tests are the preferred ones. Alternatively it can be also acquired good results with indirect test such as no load and short circuits, as presented in IEEE 115 Method 4: Open Circuit and Short Circuit Loading, page 73. Similar methods are adopted by many countries' Norms. In Brazil, NBR 5052 describes it in its page 22. It consists in determining temperature elevation confirmed in no load and short circuit tests. Temperature elevation sum after deducing a value of elevation provoked by ventilation determines elevation in the stator. In machines with water-cooled armature only elevation of the short circuit test must be considered, because coolant practically eliminates the iron heating influence in winding.

Rotor: The determination of rotor temperature elevation can be done by:

- Field being fed with current equal to that one necessary to keep the generator in conditions of rated load with previously specified power factor. This could be done with machine excited on no load or in short circuit, but any of two tests could cause damages in the generator (See IEEE 1151995 on page 73 )

- Data obtained in no load or short circuit tests we can do extrapolation to obtain full load temperature elevation. Therefore, the problem consists in accurately determining the value of full load excitation current with power factor similar to that one specified in project. IEEE 115 Test Procedures present two methods to determining load field current

- Brazilian Technical Normalization Association (ABNT) presents in NBR5052 several methods emphasizing ASA method
Finally, a discussion about General Method as understood this one is theoretically the correct. Next item presents a critical discussion about the three previously mentioned methods.

Excitation current determination by Fasorial analysis method for salient poles: This method corresponds to reactance or flux superposition method. Magnetic and electrical parameters are decomposed in direct and quadrature axis. It was originally presented by Blondell.

This description is similar with IEEE-115 item 5.3.3: Suppose $\mathrm{SG}$ with $\mathrm{V}$ (phase), $\mathrm{I}_{\mathrm{a}}$ and power factor $\cos f$. $I_{a}$ is decomposed in direct $I_{d}$ axis and quadrature in $\mathrm{I}_{\mathrm{q}}$ one (Fig. 1). Quadrature axis forms an angle $\mathrm{Y}$ with $\mathrm{I}_{\mathrm{a}}$ and can be calculated by the expression:

Arctang $\mathrm{Y}=\left(\mathrm{V} \operatorname{senf}+\mathrm{I}_{\mathrm{a}} \mathrm{x}_{\mathrm{q}}\right) / \mathrm{V} \operatorname{cosf}$

The $\delta$ power angle between $\mathrm{E}_{\mathrm{f}}$ and $\mathrm{V}$ is:

$\delta=\Psi-\phi$

Thus, $I_{q}$ and $I_{d}$ current could be calculated as:

$\mathrm{I}_{\mathrm{q}}=\mathrm{I}_{\mathrm{a}} \cos \Psi \angle \delta$

$\mathrm{I}_{\mathrm{d}}=\mathrm{I}_{\mathrm{a}} \operatorname{sen} \Psi \angle\left(\delta-90^{\circ}\right)$

No-load voltage to keep $\mathrm{V}$ in generator terminals could be calculated by expression:

$\mathrm{E}_{\text {fns }} \angle \delta=\mathrm{V} \angle 0^{\circ}+\mathrm{r}_{\mathrm{a}} \mathrm{I}_{\mathrm{a}} \angle \phi+$

$+\mathrm{jx}_{\mathrm{qns}} \mathrm{I}_{\mathrm{q}} \angle \delta+\mathrm{jx}_{\mathrm{dns}} \mathrm{I}_{\mathrm{d}} \angle\left(\delta-90^{\circ}\right)$

where, $\mathrm{x}_{\mathrm{dns}}$ and $\mathrm{x}_{\mathrm{qns}}$ are non-saturated direct and quadrature synchronous reactance, respectively.So $E_{\text {fns }}$ value is non-saturated one.

Error correction due to saturation will be presented now.

As it is possible to verify in Fig. 1, Ef is determined in air gap linear curve or, in other words, it is supposed to be Linear Magnetic Circuit.

It is possible obtain $\mathrm{F}_{\text {fns }}$ with $\mathrm{E}_{\text {fns }}$.

Resultant $\mathrm{E}_{\mathrm{R}}$ voltage and $\mathrm{F}_{\mathrm{R}}$ flux allow determining saturation by as below presented:

$E_{R}=V+r_{a} I_{a}+j x_{1} I_{a}$

where, $E_{R}$ determines the correction of saturation effect. It is the difference between air gap and saturation curve in Fig. 2. $\mathrm{DF}_{\mathrm{f}}+\mathrm{F}_{\text {fns }}=\mathrm{Ff}$ sum is mmf field necessary to keep alternator under specified conditions. 


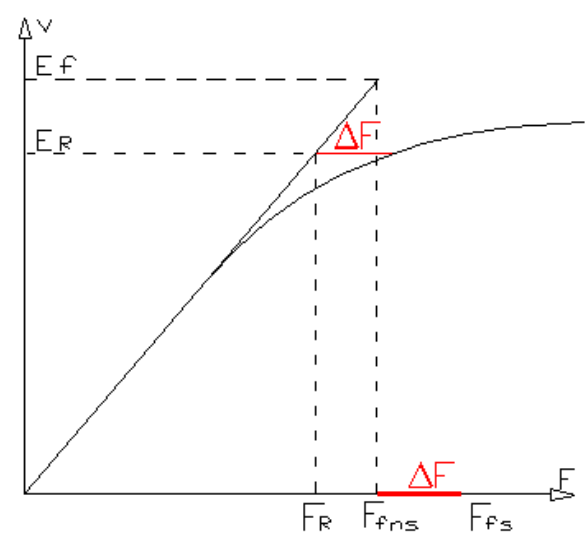

Fig. 2: Saturation correction

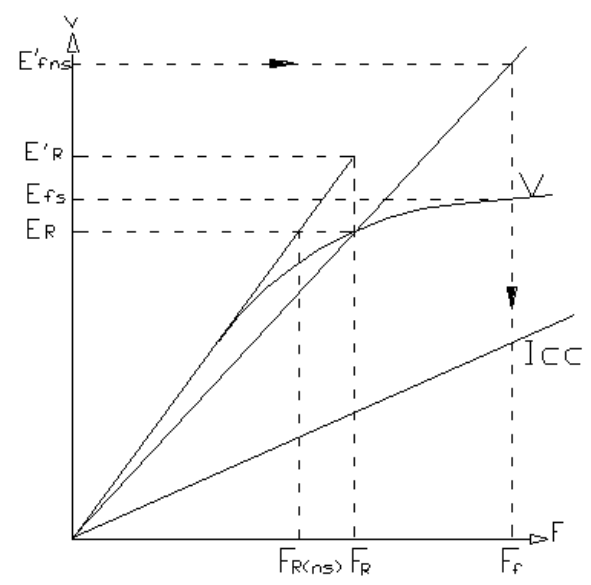

Fig. 3: Linear $M C$ in $E_{R}$

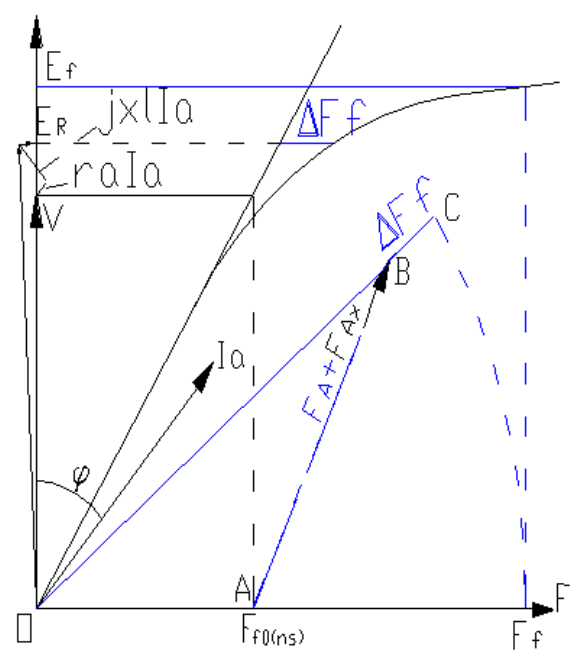

Fig. 4: $\mathrm{I}_{\mathrm{f}}$ Determination by ASA method
This method presents reliable results, however it does not correspond to the physical reality since neither machine works in air gap line nor correction obtained by $\mathrm{DF}_{\mathrm{f}}$ sum corresponds to physical reality.

Another way to considering the saturation effect is to suppose linear $\mathrm{MC}$ in $\mathrm{E}_{\mathrm{R}}$. Correction is made with $\mathrm{K}=\mathrm{E}_{\mathrm{R}}{ }_{\mathrm{R}} / \mathrm{E}_{\mathrm{R}}$. Results with this method are reliable but again it is not in conformity with physical reality.

Now description of this correction is presented. $\mathrm{x}_{\mathrm{d}(\mathrm{s})}$ in $\mathrm{E}_{\mathrm{R}}$ point is calculated by dividing $\mathrm{x}_{\mathrm{d}(\mathrm{ns})}$ for $\mathrm{K}$, excluding $\mathrm{x}_{1}$ (leakage reactance) because leakage flux ways are predominantly in air. The reactance $x_{q}$ is not corrected because most part of quadrature flux way is in air. If $\mathrm{E}_{\text {fns }}^{\prime}$ is the voltage in Linear New Magnetic Circuit (fictitious) expression (7) could be wrote like expression (5) but with $\mathrm{x}_{\mathrm{ds}}$ instead $\mathrm{x}_{\mathrm{dns}}$ :

$\mathrm{E}_{\text {fns }}^{\prime} \angle \delta=\mathrm{V} \angle 0^{\circ}+\mathrm{r}_{\mathrm{a}} \mathrm{I}_{\mathrm{a}} \angle \phi+\mathrm{jx}_{\mathrm{q}} \mathrm{I}_{\mathrm{q}} \angle \delta$

$+\mathrm{jx}_{\mathrm{ds}} \mathrm{I}_{\mathrm{d}} \angle \phi-90^{\circ}$

where, $E_{\text {fns }}$ was determined by $\mathrm{mmf}_{\mathrm{f}}$, which can be found in abscissa axis with a perpendicular in $E_{\text {fns. }}^{\prime} E_{f}$ value can be found in saturation curve. Figure 3 analysis confirms previously explanation.

Graphical method by using poitier (corresponding to ASA Method): IEEE 115-1995 5.35, pages 58-60, describes this method but limited to SG non-salient poles. ABNT NBR 5052, page 39, describes as ASA Method but not limited to non-salient poles. Langsdorf also describes it in his Theory of Electrical Machines of Alternating Current in pages 447-449.

This very used method sums mmf's corresponding to nominal voltage in air gap line $\left(\mathrm{F}_{\text {fons }}\right)$ with $\mathrm{mmf}$ to keep the machine in short circuit with nominal current $\left(F_{A}+F_{x}\right)$. If $F_{f 0 n s}$ is reference, $(90+f)$ is $\left(F_{A}+F_{x}\right)$ angle. In order to obtain $\mathrm{F}_{\mathrm{f}}, \mathrm{DF}_{\mathrm{f}}$ value must add in $\left(\mathrm{F}_{\mathrm{fons}}+\right.$ $\left(F_{A}+F_{x}\right)$ ). That value is the difference between $\mathrm{mmf}$ corresponding to $E_{R}$ in saturation curve and air gap line. $E_{R}$ value is graphically calculated as showed in Fig. 4.

Values obtained in this method are reliable. Meanwhile there is not theoretical sustentation because the method neither corresponds to physical reality nor math model: There are not a physical correspondence with $\mathrm{DF}_{\mathrm{f}}$ values.

On the other hand, it is not necessary to do mmf composition in linear MC (air gap line); it can be made with real values. In General Method presented in 2.2.3 the subject is better explored. 


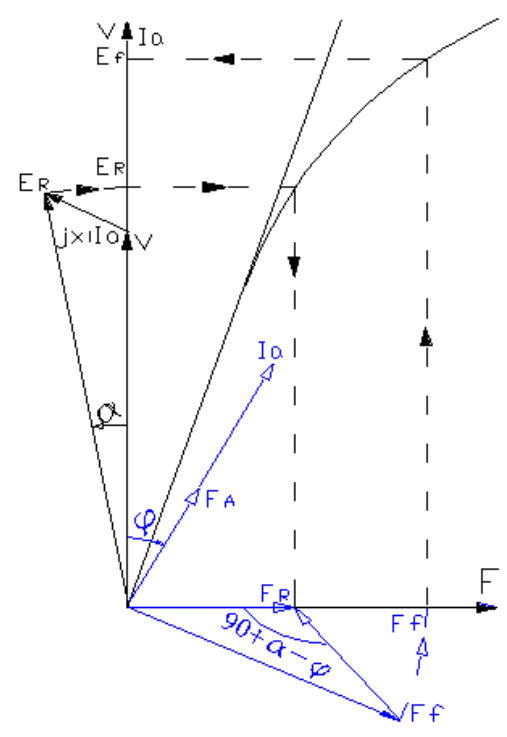

Fig. 5: General method for non salient poles

\section{General method:}

Non salient poles: In this method, true mmf, $F_{f}$ and $F_{A}$ act inside $\mathrm{MC}$ and they are added to obtain $\mathrm{F}_{\mathrm{R}}$ resultant, which allows finding $E_{R}$. To calculate terminal voltage it is necessary considerer resistive and leakage voltage fall.

Since leakage flux acts just in part of MC whose air way is large, $\mathrm{F}_{1}$ effect can be replaced by $\mathrm{x}_{1} . \mathrm{I}_{\mathrm{a}} ; \mathrm{x}_{1}$ is calculated in project or experimentally determined for example with Poitier Method which presents some errors but acceptable for almost all Norms. $F_{A}$ is calculated in project or determined experimentally by Poitier method too.

Usually it is necessary to calculate $F_{\mathrm{f}}$ in order to guarantee terminal voltage with load $\mathrm{I}_{\mathrm{a}}$ and cosf power factor.

In order to calculate $F_{R}$ it is necessary to know $E_{R}$, which can be done with Equation (6) or graphically as showed in both Fig. 4-5. $\mathrm{F}_{\mathrm{f}}$ is obtained with the expression:

$F_{f}=F_{R}-F_{A}$

where, $F_{f}$ allows finding $E_{f}$ in no load voltage curve.

Graphically: after obtaining $E_{R}$ to determine $F_{R}$ in abscissa axis, a composition $F_{R}$ with $-F_{A}$ is accomplished; angle should be $90^{\circ}+\alpha-\phi . \mathrm{F}_{\mathrm{f}}$ value allows to determine $\mathrm{E}_{\mathrm{f}}$. Therefore to non salient poles SG, calculation is very simple but with physical correspondence.

General method: Salient poles: In salient SG pole it is not possible to do $\mathrm{F}_{\mathrm{f}}$ and $\mathrm{F}_{\mathrm{A}}$ direct composition because acting in $\mathrm{MC}$ with different permeances and $\mathrm{F}_{\mathrm{A}}$ also changes constantly of angular position. Decomposition in two axes: Direct and quadrature always allows offering the different but constant permeance to each one if saturation is not considered.

$F_{d}$ is $F_{A}$ component in direct axis and it can be calculated as:

$$
\mathrm{F}_{\mathrm{d}}=\mathrm{F}_{\mathrm{A}} \operatorname{sen} \Psi
$$

And it can be added with $F_{f}$ because both are in the same axis. It is necessary to observe: $F_{f}$ has a rectangular spacial distribution, while it is not considered spacial harmonics because of pole design in air gap, which has variable value and increasing from center (d line) to extremity (q line), so permeance decreases and it is possible obtain sinusoidal flux. But $F_{A}$ and consequently $F_{d}$ are practically sinusoidal and when it is applied to a variable permeance the resultant flux will contain harmonics. In this study it is just considered fundamental. However it is necessary to consider a correction for Fd value as proposed by J. A. Shouten. The expression:

$\mathrm{F}_{\mathrm{d}}=0.9 \mathrm{~K}_{\mathrm{e}} \cdot \mathrm{N}_{\mathrm{s}} \cdot \mathrm{I}_{\mathrm{a}} /$ polos. $\cos \Psi$

Will be replaced by:

$\mathrm{Fd}=0.765 \mathrm{~K}_{\mathrm{e}} \cdot \mathrm{N}_{\mathrm{s}} \cdot \mathrm{I}_{\mathrm{a}} /$ polos $\cos \Psi$

$\mathrm{F}_{\mathrm{q}}$ is $\mathrm{F}_{\mathrm{A}}$ component in quadrature axis and it can be calculated as:

$\mathrm{Fq}=\mathrm{F}_{\mathrm{a}} \cos \Psi$

Applied in inter-polar space which has a small and irregular permeance, it results in flux with strong harmonics prevailing third and multiples one. To do composition of $\mathrm{F}_{\mathrm{q}}$ with other $\mathrm{mmf}$ it would be necessary, to replace it by a corresponding value that considered MC homogenous. This value depends on width of face pole referred to pitch pole.

It can prove:

Pole arch/Pole pitch $=0,6: \mathrm{F}_{\mathrm{q}}=0,44 \mathrm{~F}_{\mathrm{A}} \cos \mathrm{Y}$

Pole arch/Pole pitch $=0,7: \mathrm{F}_{\mathrm{q}}=0,53 \mathrm{~F}_{\mathrm{A}} \cos \mathrm{Y}$

No considering harmonics implies in $12 \%$ error in $\mathrm{F}_{\mathrm{q}}$ but it reflects with lower value than $1 \%$ in terminal voltage. However in this $\mathrm{MC}$ air part prevail so $\mathrm{F}_{\mathrm{q}}$ effect can be calculated with $\mathrm{x}_{\mathrm{Aq}}$ reactance. Therefore it is possible to calculate: 


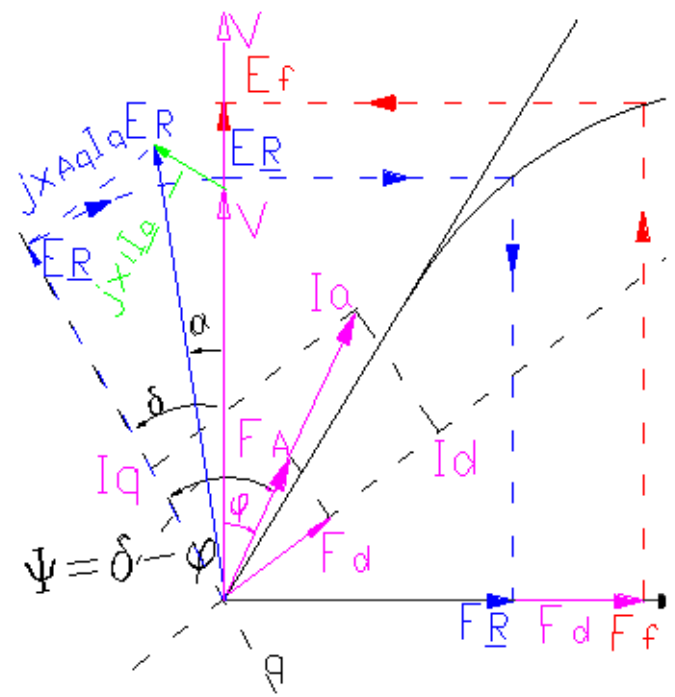

Fig. 6: $\mathrm{E}_{\mathrm{f}}$ determination-salient poles $\mathrm{SG}$

$$
\mathrm{E}_{\mathrm{Aq}}=\mathrm{jx}_{\mathrm{Aq}} \mathrm{I}_{\mathrm{q}}=\mathrm{j}\left(\mathrm{x}_{\mathrm{q}}-\mathrm{x}_{1}\right) \mathrm{I}_{\mathrm{q}}
$$

Calculation method: To determine field current that allows working with nominal voltage and current as well as determined power factor, steps are:

- Also to determine voltage in $E_{R}$ air gap by expression (6) or graphically as presented in Fig. 6

- Value in direct axis is:

$E_{\underline{R}}=V+j x_{1} I_{a}+j\left(x_{q}-x_{1}\right) I_{q}$

It is possible to prove $E_{R}$ is in quadrature axis and $\mathrm{F}_{\underline{R}}$ is in direct axis and this value can be determined in no load curve.

- c) $\mathrm{F}_{\mathrm{Ad}}$ and $\mathrm{F}_{\mathrm{R}}$ compositions allows calculating $\mathrm{F}_{\mathrm{f}}$ or $\mathrm{I}_{\mathrm{f}}$.

- d) $F_{f}$ or $I_{f}$ in no load curve allows determining $E_{f}$.

\section{RESULTS}

Two successful cases are presented that justify repower.

Case 1 is only presented to emphasize parameters changed and do not changed.

Case 2 is used to discuss three methods to determining field current in load with determined power factor and comparing it with real value.

Case 1: GGE (CEMIG) Generator repowered by WEG: Before and after repower data are presented in Table 3.
Consideration about stator and rotor manufacture and isolation: Stator windings were made with isolated rectangular bars including large cotton layers with asphalt impregnating replaced by another with isolated bars including fine polyester or fiber glass layers with material as Nomex created by Dupont in the 70s. It is done of variant synthetic para-aramid fibers and polymers, or similar as Klevar for $\mathrm{F}$ or $\mathrm{H}$ class. The change of isolation and consequent reduction of its thickness allows increasing copper amount.

Field winding conductors were also replaced by other isolated for F. Insulation material change allowed increasing conductor section.

Current density increasing based on the temperature elevation and/or conductor section increasing allowed enhancing generator capacity in $31 \%$.

Other considerations will be done in Case 2. Parameters of generator had changed values according to expectation: All reactances increased in $30 \%$ as presented in Table 4.

Mechanical considerations: Thirty-one percent of SG power increasing obliges to evaluate the main mechanical parts, according Tables 9-11, that could be affected by power increasing.

Rotor-axis set: Analysis of combined torsion (resulting of torque application) and flexion (resulting of rotating mass action, magnetic thrust of rotor in relation to stator and turbine radial hydraulic thrust) efforts showed that mechanical structure can support the new power and fatigue resistance.

Rotor-axis key and generator-turbine wheel axis: It was possible to keep safety margin expected with new voltages of key compression side and shear stress voltages.

Stator nucleus and frame: Buckle was analyzed and verified if structure supportability was assured.

Ventilation System: On repower, if nucleus plates are not changed, number of ventilation ducts and system are kept. Other considerations will be done in Case 2.

Case 2: GE Generator $n^{0}$ 1-EMAE-at Henry Borden Power Plant repowered by ABB: Thirty-three MVA generator repower allowed an increase of $30 \%$ of power as showed Table 5.

Considerations about electrical project: Table 5 presents characteristics of earlier machine and after repower. 
Am. J. Applied Sci., 8 (6): 594-602, 2011

Table 3: Before and after repower data

\begin{tabular}{lll}
\hline & Before & After \\
\hline Power kVA & 28241 & 36948 \\
Nominal Voltage & $13800 / 7977 \mathrm{~V}$ & $13800 / 7977 \mathrm{~V}$ \\
Nominal current & $1182 \mathrm{~A}$ & $1547 \mathrm{~A}$ \\
Frequency/revolutions & $60 \mathrm{~Hz} / 300 \mathrm{rpm}$ & $60 \mathrm{~Hz} / 300 \mathrm{rpm}$ \\
per minute & & \\
Power factor & 0,95 & 0,95 \\
Excitation & Brushes & Brushes \\
Class/Elevation(stator) & $\mathrm{B} / 60^{\circ}$ & $\mathrm{B} / 60^{\circ}$ \\
Channels-Total & 288 & 288 \\
Channel per pole/pitch & $12 / 1-11$ & $12 / 1-11$ \\
Channel size & $23 \times 118 \mathrm{~mm}^{2}$ & $23 \times 118 \mathrm{~mm}^{2}$ \\
Parallel circuit & 4 & 4 \\
Conductor (size) & $6(3 \times 4,8) \mathrm{mm}^{2}$ & $i$ \\
Current Density & $3.42 \mathrm{~A} / \mathrm{mm}^{2}$ & $i$ \\
Slot utilization factor & 0,45 & $i$ \\
Class/Elevation (rotor) & $\mathrm{B} / 60^{\circ}$ & $\mathrm{F} / 0^{\circ}$ \\
Conductor(size) & $58(3,7 \times 3) \mathrm{mm}^{2}$ & $58(3,7 \times 3) \mathrm{mm}^{2}$ \\
Class/Elevation (rotor) & $\mathrm{B} / 60^{\circ}$ & \\
Conductor (size) & $58(3,7 \times 3) \mathrm{mm}^{2}$ & \\
\hline
\end{tabular}

Table 4: Generator parameters before and after repower

\begin{tabular}{lll}
\hline & Saturated & Not Saturated \\
\hline $\mathrm{Xd}-$ & $0.71 / 0.76$ & $0.9192 / 0.9955$ \\
$\mathrm{Xq}-$ & $0.43 / 0.46$ & $0.5604 / 0.604$ \\
Xo & $0.05 / 0.05$ & $0.07 / 0.07$ \\
$\mathrm{X} 2$ & $0.15 / 0.16$ & $0.2 / 0.2$ \\
X'd & $0.171 / 0.173$ & $0.2241 / 0.2269$ \\
X',d & $0.162 / 0.164$ & $0.2117 / 0.2146$ \\
X',q & $0.145 / 0.148$ & $0.1901 / 0.1938$ \\
Td' & $0.7291 / 0.7337$ & $0.8046 / 0.8101$ \\
Tdo' & $3.0354 / 3.2506$ & $3.3255 / 3.5816$ \\
Td', & $0.0511 / 0.0606$ & $0.0504 / 0.0606$ \\
Tdo', & $0.0615 / 0.0635$ & $0.0613 / 0.0635$ \\
Ta & $0.1616 / 0.1641$ & $0.1614 / 0.1641$ \\
\hline
\end{tabular}

Table 5: Before and after repower characteristics

\begin{tabular}{lll}
\hline & Before & After \\
\hline Power & $33 \mathrm{MVA}$ & $43 \mathrm{MVA}$ \\
Nominal voltage & $11000 \mathrm{~V}$ & $11000 \mathrm{~V}$ \\
Nominal current & $1734 \mathrm{~A}$ & $2260 \mathrm{~A}$ \\
Frequency/Rotation & $60 \mathrm{~Hz} / 300 \mathrm{rpm}$ & $60 \mathrm{~Hz} / 300 \mathrm{rpm}$ \\
Power factor & 0,95 & 0,95 \\
Excitation & Generator CC: & Generator CC \\
& $200 \mathrm{KW} 300 \mathrm{~V}$ & $200 \mathrm{KW} 300 \mathrm{~V}$ \\
Class/Elevation (stator) & $\mathrm{B} / 60^{\circ}$ & $\mathrm{B} / 60^{\circ}$ \\
$\mathrm{x}_{\mathrm{d}}$ & & 1,386 \\
$\mathrm{x}_{\mathrm{q}}$ & & 0,8316 \\
\hline
\end{tabular}

Table 6: Thirty-three MVA generator load test

\begin{tabular}{llllll}
\hline V & I & P & Q & If & Vf \\
Line $(\mathrm{V})$ & Line $(A)$ & $(\mathrm{MW})$ & $(\mathrm{MVAR})$ & $(\mathrm{A})$ & $(\mathrm{A})$ \\
\hline 10900 & 1750 & 28.7 & 15.76 & 410 & $215 \mathrm{~s}$ \\
\hline
\end{tabular}

Table 7: 34,6 MVA load test

\begin{tabular}{|c|c|c|c|c|c|c|c|}
\hline $\mathrm{V}$ & I & $\mathrm{P}$ & Q & & & Dt & $\mathrm{Dt}$ \\
\hline Line & line & MW & MVAR & If & Vf & (1) & (2) \\
\hline 11029 & $18100,8 \mathrm{pu}$ & 29.6 & 18 & 510 & 175 & 65 & 69 \\
\hline
\end{tabular}

Table 8: 46.8 MVA load test

\begin{tabular}{llllllll}
\hline V & I & P & Q & & & Dt & Dt \\
Line & line & MW & MVAR & If & Vf & (1) & (2) \\
\hline 11192 & 2434 & & & & & & \\
1,0174 & 1,077 & 40 & 24 & 646 & 240 & 90 & 93 \\
\hline
\end{tabular}

Table 9: Mechanical Values

\begin{tabular}{llc}
\hline & Symbol & Calculated value \\
\hline Cut tension & $\mathrm{Tn}$ & $18.2 \mathrm{~N} \mathrm{~mm}^{-2}$ \\
Flexion tension & $\sigma_{\mathrm{n}}$ & $19.2 \mathrm{~N} \mathrm{~mm}^{-2}$ \\
Von mises tension & $\sigma_{\mathrm{VMn}}$ & $36.9 \mathrm{~N} \mathrm{~mm}^{-2}$ \\
Average tension & $\sigma_{\text {medio }}$ & $31.5 \mathrm{n} \mathrm{mm}^{-2}$ \\
Alternating tension & $\sigma_{\text {altermado }}$ & $19.2 \mathrm{n} \mathrm{mm}^{-2-}$ \\
Axe fatigue resistance & & \\
Tension & $\sigma_{\text {fed }}$ & $68.8 \mathrm{n} \mathrm{mm}^{-2}$ \\
Fatigue safe factor & FSt & 3.4 \\
\hline
\end{tabular}

Repowered project analysis allows interesting conclusions:

- In stator, conductor section was increased in $15 \%$, from $822.31-946.37 \mathrm{~mm}^{2}$ and current density from $2.10 \mathrm{~A} / \mathrm{mm}^{2}$ to $2.38 \mathrm{~A} / \mathrm{mm}^{2}$ that represents $13.3 \%$ Bars have also been changed by Robell bar type. Repower happened by increase of conductor section and increase of density Data analysis allows concluding density current increase (13.3\%) is perfectly bearable by new temperature class.

- In earlier rotor, conductor section was of $4,064 \times 50.8=206.45 \mathrm{~mm}^{2}$.

In repower, conductor section changed to $5 \times 50=$ $250 \mathrm{~mm}^{2}$ represents an increase of $21 \%$ but turn number was reduced from 62.5-50, to not surpass voltage excitation system capacity.

The reduction of turn number of field winding was necessary to limit field voltage, because the excitation voltage must be limited to earlier power one.

In order to identify the impact in rotor it is necessary to calculate the projected current value in the new power. The company that did repower, ABB used ASA method adopted by NBR 5052. Before repower field current by indirect method was calculated and confirmed in load test with $10.900 \mathrm{~V}, 1.750 \mathrm{~A}, 32.7 \mathrm{MVA}$ and power factor 0.878 , according to Table 6 .

Current value found by ASA method (Indirect) was 398A, representing 3\% lower than experimental results. After repower the load test was made with $11,029 \mathrm{~V}, 1,810 \mathrm{~A}, 34.6 \mathrm{MVA}$, Inductive factor of power 0.855 , according to Table 7 .

Current value found by ASA method (indirect) was $520 \mathrm{~A}$ representing $2.0 \%$ higher than experimental results.

Test was repeated with $11,192 \mathrm{~V}, 2,434 \mathrm{~A}$, 46.8MVA and power factor of 0.855 according table 8 . The current value found by indirect method was $630 \mathrm{~A}$ that represents $2.5 \%$ lower than experimental results. 
Am. J. Applied Sci., 8 (6): 594-602, 2011

Table 10: Mechanical values

\begin{tabular}{lcc}
\hline & Symbol & Calculated value \\
\hline $\begin{array}{l}\text { Contact force between } \\
\text { key and axis }\end{array}$ & $\mathrm{F}$ & $2988456 \mathrm{~N}$ \\
$\begin{array}{l}\text { Compressive Tension } \\
\text { in key side }\end{array}$ & $\sigma_{\mathrm{C}}$ & $47.7 \mathrm{~N} \mathrm{~mm}^{-2}$ \\
Key Cut Tension & $\sigma_{\mathrm{c}}$ & $14.6 \mathrm{~N} \mathrm{~mm}^{-2}$ \\
\hline
\end{tabular}

Table 11: Mechanical values

\begin{tabular}{lll}
\hline & Symbol & \\
\hline $\begin{array}{l}\text { Contact force between } \\
\text { key and axis }\end{array}$ & $\mathrm{F}$ & $2087681 \mathrm{~N}$ \\
$\begin{array}{l}\text { Compressive Tension } \\
\text { in key side }\end{array}$ & $\sigma_{\mathrm{C}}$ & \\
Key Cut Tension & & $85.2 \mathrm{~N} \mathrm{~mm}^{-2}$ \\
\hline
\end{tabular}

Experimental results confirm ASA method with reasonable precision justifying its use by $\mathrm{ABNT}$ and also for salient poles machines. Besides, in spite of the fact this method presenting reliable results, it does not have theoretical sustentation. IEEE 115-95 only adopts it for non salient pole machines.

For salient poles Reactance method was adoptedItem 5.3.3, "Phasor diagram analysis salient polo machine", pages 54/55.

Repeating excitation current calculation by "Phasor diagram analysis corrected" method, values are:

- $\quad$ For 34.6 MVA - If = 515 A

- $\quad$ For $46.8 \mathrm{MVA}-$ If $=635 \mathrm{~A}$

These values are very close to those ones determined in respective load tests as well as by ASA method.

Finally solution by General Method is presented with the following results:

- For 34.6 MVA - If=510 A

- For 46.8 MVA - If=630 A

The three methods present very close values. Thus, they are used without problems under their practice application

Determination of temperature elevation in generator field with no load and short circuit tests presents reliable values.

In this study theoretical methods sustentation discussing in admitting there is physical correspondence close to reality just in General Method.

Considerations about stator rotor manufacture and isolation: The impregnating during coils manufacture have to be a vacuum/pressure, combining synthetic epoxy- and polyester-base resin with solid mica-base .material insulation.
Insulating tape is the essential part of MICADUR technique and it consists of a fine fiber glass layer that serves as base for mica study. Both materials are joined with epoxy base resin.

The impregnating was accomplished by vacuum pressure process in order to guarantee air absence.

External completion is done with anti-corona painting and application of low resistivity epoxy base varnish, allowing a suitable ground of nucleus isolation. In bar extremities a high resistivity cover is used to reduce winding superficial voltage gradient.

Considerations about mechanical project: Power increased from 33 to 43 MVA implies in corresponding mechanical requesting increase.

The main concerning is presented now:

Axle: A horizontal axle unit engaged by two Pelton turbines is submitted to two combined torsion (resulted of binary pair application) and flexion (caused by masses action of rotating parts, magnetic thrust of rotor in relation to stator and radial hydraulic thrust of turbine) efforts.

It was calculated maximum axle effort and fatigue resistance and the following results were obtained:

Axis calculations results of Results of rotor axis key calculation

Analysis of obtained parameters can guarantee key is able to transmitting new power.

Results of key generator axis calculation-Turbine wheel Observation: As rotation was not modified it was not necessary proceed the new calculation in poles mechanical efforts.

Calculation of stator nucleus buckle: Calculation of stator nucleus buckle was done with software whose data input in program consist of component stator nucleus and supporting structure geometry. Other necessary data are: Nucleus temperatures, heat air in air gap and support elasticity. Simulation results have indicated some buckling possibility inside nucleus plates after repowering. The same happened before repowering. Obtained results before repower are:

$\mathrm{FS} 1=2.96 ; \mathrm{FS} 2=1.64 ; \mathrm{FS} 3=1.79$

Obtained results after repower are:

$\mathrm{FS} 1=2.65 ; \mathrm{FS} 2=1.35 ; \mathrm{FS} 3=1.44$ 
Am. J. Applied Sci., 8 (6): 594-602, 2011

Criteria established by manufacturer:

- $\quad F S<1$ : surely there will be buckle of nucleus plates

- $1<=\mathrm{FS}<2$ : uncertain region (buckle can happen or not)

- $2<=$ FS: Certainly buckle will not happen

Structure efforts calculation provoked by thermal expansion: Results obtained by using computer program indicates mechanical tension caused by thermal expansion:

- Machine with nominal temperature- Maximum = $3,18 \mathrm{kgf} / \mathrm{mm} 2$

- Machine with average $\Delta \mathrm{t}$ with magnetic pilingMaximum $=5,48 \mathrm{kgf}$. $\mathrm{Mm}^{-2}$

- Machine with average $\Delta \mathrm{t}$ without magnetic pilingMaximum = 4,15 kgf. $\mathrm{Mm}^{-2}$

Calculated values by program are too conservative for split structures as it happens in presented case and expansion effect by heating is better absorbed in this case based on flexibility of existent elements.

\section{CONCLUSION}

This study emphasizes the repower validity of for several reasons.

New power guarantee: According to everything presented in here it is possible to confirm nowhere in the machine if the temperature exceeds limits before definitive test of loading generator connected to the system. The main concerning was the field windings but calculations done in any presented methods resulted in very similar values assuring reliability to them. Presented and identified methods are:

ASA (or graphic methods by using Poitier according to IEE-115),

Flux superposition (method identified in IEEE115-95 as Fasorial Analysis for salient poles to determine excitation current) do not have a great theoretical support, however they have reliable results.

General Method presents excellent results, in agreement with physical behavior.

It must be emphasized calculations done in a similar way in other machines from Henry Borden Power PlantCubatão/SP always confirm results are reliable as compared with values presented in loading tests.

Isolation guarantee: The new isolation has at least presented lifetime equal to original by using stable materials and applied with techniques that guarantee none contamination.
Mechanical guarantee: It was verified critic points due to the effort increasing provoked by power the increasing.

It is important to care:

- Key: It must be verified all efforts in the new power. In all cases presented values were within the safety margin.

- Axis: It was verified all efforts in the new power. Insured values were within the safety margin

- The Stator Buckle: This was one of the main concerning and was verified with care in applying appropriated software. Result indicates the possibility of stator buckle as also indicated in early machine

The liberation for work was based on two verifications:

c1: Similar indication in early machine with long work time without problem indications;

c2: Pessimistic presented calculations by program for split structures.

Payback guarantee: Finally, a comparison between repower and new machine acquisition is important. The following values are updated to 2007, in American dollars: Costs to repower a 33MVA Generator , 360 rpm and 20 poles for 43 MVA is U\$ $2,400,000.00$. The value of a new generator with the same characteristics is U\$ 4,500,000.00. The comparison confirms financial repower is valid.

Sustainability guarantee: In times of environmental awareness it is necessary to make every effort to recycle raw materials. Repowering 10 hydro generators provided increase of $129 \mathrm{MW}$ from 453 to $581 \mathrm{MW}$ practically without new raw materials, recycling frames, axes, rotors, buckles and copper. Economy of:

- 1300 ton of important materials,

- 2600 ton of raw materials,

- $5200 \mathrm{MWH}$ of Energy,

- 1000000 liters of combustible oil or

- 1400-1500 ton of coal,

- 2500 to 5000 ton less emissions of $\mathrm{CO}_{2}$, the dangerous green house gas if energy is generated with coal, oil or gas

\section{REFERENCES}

ABNT-NBR 5052, 1984. Rotating electrical machines Synchronous machines - Testing - Method of test, http://www.abntcatalogo.com.br/norma.aspx?ID=4 689 
ABNT-NBR 5117- Rotating electrical machines Synchronous machines - Specification, http://www.abntcatalogo.com.br/norma.aspx?ID=932

Bakie, E.B., B.K. Johnson, H.L. Hess, J.D. Law, 2005. Analysis of synchronous generator internal insulation failures. Proceeding of the 2005 IEEE International Conference on, ISBN: 0-7803-8987-5

Data-Book of Henry Borden Power Plant - EMAE 1992- Tests made by ABB, http://www.emae.com.br/emae/conteudo.php?id=Pe squisa-e-Desenvolvimento.

Fitzgerald, A.E., Jr,C. Kingsley and S.D. Umans, 2006. Electrical Machines. 6th Edn., Bookman. ISBN: 007-366009-4.

IEEE 115-1995 (R2002)-IEEE Guide: Test Procedures for Synchronous Machines, The Institute of Electrical and Electronics Engineers, Inc, NY, ISBN 1-55937-710-0
Kundur, P., 1994. Power System Stability and Control. MacGraw-Hill, New York, ISBN: 0-07-035958-X, pp: 1176.

Langsdorf, A.S., 2009. Theory Of Alternating Current Machinery,2/E - Mcgraw-Hill Education, ISBN: 0070994234

Petrov, V.V., Zh.P. Pogodina, S.M. Levins, N.E. Lavkin, 2009. Improving insulation for turbogenerators and large electrical machines made by vacuum-pressure impregnation,-Cat. InistFrance, INIST : 13234, 35400011024305.0050

Pyrhönen,J., T. Jokinen, V. Hrabovcová, Dec (2008. Design of rotating electrical machines. John Wiley and Sons. Ltd, DOI: 10.1002/9780470740095.index

Stone, G.C., E.A. Boulter, I. Culbert, H. Dhirani, 2004. Electrical insulation for rotating machines. IEEE, ISSN: 0093-9994 